\title{
Review of research on tobacco logistics cost based on system dynamics
}

\author{
Yuanyuan Wu ${ }^{1, a}$, Zhihua Diao ${ }^{1, b^{*}}$, Tong Zhang ${ }^{2}$, Chunying Diao ${ }^{1}$, Ke Liang ${ }^{2}$ \\ ${ }^{1}$ Electric Information \& Engineering Department, Zhengzhou university of Light Industry, No. 5 of \\ Dongfeng Road, Zhengzhou, China \\ ${ }^{2}$ Henan 863 Software Incubator Co., Ltd, No. 6 of Cuizu Street, Zhengzhou, China \\ a diaochunying1@163.com, biaozhua@163.com \\ * Chinese, Ph.D., Associate professor and a master supervisor, Zhengzhou University of Light Industry, \\ Telephone number: +86 1503832 2562, Email: diaozhua@163.com.
}

Keywords: tobacco logistics, cost, system dynamics

\begin{abstract}
After reviewing a large number of books and articles on the cost of tobacco logistics, this paper summarizes the results of the study on tobacco logistics costs. First of all, it summarizes the characteristics of tobacco logistics, which leads out the development trend of tobacco and the development of logistics cost. Combined with the research and application of system dynamics method in logistics field, the development and importance of tobacco logistics cost based on system dynamics are discussed and demonstrated in many aspects. Finally, the problems of tobacco logistics are summarized from the aspects of construction, important link, scale and management of tobacco logistics. After comparing the method of system dynamics, the advantages and importance of the latter are drawn, and made a vision and thinking about how to control the cost of tobacco logistics in the future.
\end{abstract}

\section{Introduction}

In the process of rapid economic development and the arrival of the information age, the first and second profit sources continue to be constrained by advanced science and technology. After the growing supply of these two sources of profits, the famous from Japan Waseda University Professor Xi Ze repair in 1970, edited by the "circulation costs," a book put forward the "little-known third profit source", This concept is to reduce logistics costs. With the development of society, people gradually realize that logistics costs was a major source of profit, and its savings can bring unexpected economic benefits to enterprises and even society. How to control logistics costs while saving was also causing people's attention. But in terms of China's current logistics situation, logistics still has a high cost, how to reduce logistics costs is still a difficult task.

In 2001, China's accession to the WTO, tobacco products tariff was reduced, quota and license control policy relaxed or even cancelled, the tobacco market was growing in full bloom, foreign tobacco authority ushered in fierce competition and challenges. In order to roots to survive in the fierce international competition and to achieve the sustainable development, the tobacco industry improved production and sales management system, at the same time it will focus attention on the problem of restricting the development of the whole industry on logistics. In 2004, China National Tobacco Monopoly Bureau specially set up a leading group of modern logistics construction, tobacco industry enterprises and tobacco commercial enterprises all over the country have also promoted the modernization and management of the tobacco logistics industry, China's achievements in the tobacco industry have made China to be a typical representative of the modern logistics and national economy.

Although China has made underestimated achievements in the modernization of tobacco logistics, there are some problems that can't be ignored in management. For example, the scale of enterprise logistics was small, it was difficult to control the cost of inventory and the flow of information in logistics process, It was not only an important factor to control the cost of tobacco logistics and improve service level, and it has become the tobacco industry to achieve sustainable 
development obstacles, and it has become the obstacles to sustainable development, urgently need to be solved in time.

The following will summarize the existing research results from the three aspects of the characteristics and development trends of tobacco logistics, logistics costs, research status at home and abroad, and the application of system dynamics in the logistics field. At the same time, we would analyzes the problems existing in the research of the tobacco logistics cost based on system dynamics, and looks forward to the development of the logistics cost.

\section{The characteristics and development trends of tobacco logistics}

Tobacco logistics is an important component of social logistics, and the main logistics activities are achieved through storage, distribution and delivery. At present, the tobacco logistics system is usually divided into tobacco commercial logistics and tobacco industry logistics two subsystems. The tobacco industry belongs to the state monopolized industry, and it was a very special existence in China. It was also an important component of China's national economy and an important source of fiscal revenue. The implementation of the regional administration and the vertical management of the tobacco industry, with the planned economy representative characteristic, namely, control of the province's tobacco companies specialized industrial enterprises (including supporting material factory, cigarette factory, cigarette and cigarette auxiliary materials for cigarette production and distribution). Tobacco Monopoly Bureau specially governs the tobacco commercial enterprises (including the municipal and county tobacco companies, responsible for sales, transportation, logistics management, information collection market etc.).

The construction of tobacco industry in foreign countries is relatively early, and the market is mature, and the construction of logistics system is relatively complete. On the one hand, the reason stems from the continuous implementation of mergers and acquisitions and business integration strategy of transnational tobacco companies. On the other hand, it also has a strong relationship with the mature construction of its modern logistics system. Especially in Europe, Britain and Japan tobacco industry, it is through the construction of modern logistics perfect to withstand the invasion of foreign cigarettes, and its logistics construction experience is worth learning and reference. For example, the United States and Britain's tobacco industry through the construction of a unified logistics strategy, and industrial and commercial links are closely linked in the self-logistics to play their respective advantages, industrial enterprises to learn from a strong business logistics network experience, business enterprises learn from mature Logistics management knowledge, to achieve complementary style of logistics, take the road of industrial and commercial integration. European Tobacco by creating a rapid supply chain system in Europe to enhance customer service levels, thus a large extent to explore the potential value of the tobacco industry. Japan from 1985 to withdraw the tobacco monopoly policy has been for more than 20 years, although the experience constantly against multinational companies, but Japan Tobacco still holds $75 \%$ of the national market weight, most experts considered completely independently of Japan tobacco industry has strong market control originated from its distribution of modern logistics network system and the third party logistics distribution system [1].

The development of tobacco logistics in our country has experienced a process from small space to large area, from neglect to attention. The construction of tobacco logistics follows the principles of "first enterprise, the first industry, the first cigarette material, and the first province and the other province", and the sequence is clearly carried out. In the tobacco industry, the rapid development of logistics technology and extensive application, the level is relatively high, the formula library has been used in cigarette factory automation good economic operation of the library and the library of AGV cigarette accessories transport have also been widely used, mature professional logistics operation mode also has been trying to operate in the minority area (such as Shanghai and Anhui, Hunan). The tobacco industry in various enterprises as the main object of the implementation of the internal logistics resource integration strategy, centralized management, decentralized management measures of logistics supply, production and sales of system construction and optimization, and it achieved fruitful results in the work at the same time gradually. In the part of the city between the 
province, the cigarette industrial enterprise as the core operation of the tray operation, and RFID Technology (such as Zhejiang, Jiangsu, Shanghai) combined with improve transport efficiency, reduce the number of loading and unloading of goods, the breakage rate was obviously decreased, the logistics system work efficiency has improved significantly. The development of the tobacco industry in terms of logistics business has undergone 4 stages, the first stage of network planning and Morphological initiation, the second stage of separate access and distribution to the home, the third stage of goods separation and centralized delivery, and the fourth stage of functional integration and joint distribution [2]. At present, China's tobacco companies at all levels have used more advanced computer information processing system, telecommunications access, real-time distribution, the creation of distribution centers and other advanced logistics technology has been implemented in some tobacco commercial enterprises. At the same time, the distribution centers of the prefecture level city tobacco companies are being built on a large scale, and a cigarette retail network with connectivity network and urban and rural structure has been formed. Under the encouragement and support of national policies, traditional tobacco commercial logistics is moving away from the roots of the past and rapidly moving towards modernization and information.

\section{Research status of tobacco logistics at home and abroad}

\subsection{Application and development of system dynamics in logistics research}

Earlier, logistics costs were divided into transportation costs and storage costs in two parts. D. M. Lambent argues that logistics costs can be divided into five categories, purchasing costs, warehouse occupancy costs, storage costs, order processing costs and transportation costs [3]. Christian Rossetti proposed a new classification method applicable to the global inter enterprise logistics system, based on the logistics cost method of Ellram classification [4]. Oud Manunen found that in the investigation of manufacturing enterprises and retail enterprises, logistics operations can be divided into seven types of cost [5]. Caries Griful-Miquela Starting from the logistics operation process, he believes that logistics costs can be divided into warehousing costs and transportation costs of the two major categories [6]. In general, people have different perspectives, logistics cost classification will be different, but the logistics operation process of order processing, inventory, transport-related logistics costs are still the focus of most researchers generally concerned.

On the other hand, the control of logistics cost has been a hot issue in the field of domestic and international logistics, which has produced many researches. P. S. Bender constructed a single objective programming model for commercial computer processing to help IBM companies solve supplier delivery problems, minimizing the costs of procurement, transportation and inventory [7]. Pan constructs the optimal order quantity and production lot model to solve the production system problem, and achieves the goal of controlling inventory cost [8]. W. C. Benton used the Lagrangian relaxation variable to construct a nonlinear programming model selected by the supplier to achieve the minimize of procurement cost, inventory cost and order cost [9]. S.H. Ghodsypour and C. O'Brien in order to solve the multi-procurement problem, a nonlinear programming model based on mixed integer was established, which includes price, storage, order and transportation cost [10]. Yanbo HUANG suggested that the logistics cost control idea should be carried out from the aspects of logistics cost calculation system, logistics supply chain technology optimization and logistics cost control. However, they only put forward specific ideas and did not carry out the actual in-depth study [11]. Zhaoyuan SUN constructed a logistics operation cost control packet network analysis (DEA) model [12]. Yijing HAO proposed the idea of adopting EVA management model to realize logistics cost control, and established the logistics cost control model based on ERP logic according to the actual requirements [13]. In recent years, the cost of tobacco logistics has attracted the attention of professional researchers, and there have been many valuable research methods. For example, Dezhi TANG used activity-based costing to control the cost of tobacco industry and expanded the new method to control the cost of tobacco [14]. 


\subsection{Application and Development of System Dynamics in Logistics Research}

In 1958, the system dynamics was first applied in the field of logistics, where Forrester used to solve the problems that often occurred in industry, such as stock volatility, demand amplification, imbalance between production and labor employment, and the opposite of information technology Influence, etc., and published in 1961 the book "Industrial Dynamics". After that, many scholars have applied system dynamics to logistics-related research, such as Nami and Towill [15], Berry [16] and Towel [17], Cakravastia and Diawati [18] used the dynamic analysis based on negative feedback in system dynamics, combined with the theory and technology of enterprise process reengineering, focusing on the process improvement and design of supply chain. Vos and Akkermans using system dynamics method combined with other management theory and methods (such as operational research, social science, the dynamic decision process consulting, brainstorming, engineering systems and project management, etc.), and finding the optimal system for supply chain management [19].

In the country, with the continuous improvement of the logistics industry research, more and more research scholars will apply the system dynamics method to the logistics research. In order to optimize the performance evaluation of enterprise supply chain, Su Chun proposed a simulation method based on system dynamics and balanced scorecard evaluation. At the same time, the mathematical model of service level and supply chain cost was established, and the experiments verify the efficiency of model [20]. Wenjia CHEN uses the system dynamics theory to deeply analyze the storage system principle of the distribution center, a system dynamics flow chart and relative equation system for the transportation of three shops are created. Finally, a simulation experiment was carried out with the help of computer [21]. After in-depth study of the theory of dynamics of the regional logistics system, Liping LI to create a regional logistics and regional economic system dynamics model, simulation analysis and decision and evaluation, control, and finally combined with the regional logistics case analysis of Daqing city [22]. In order to solve the total logistics transportation cost and inventory cost, Mengwei TONG established a system dynamics model from two aspects, and simulate the corresponding simulation from the perspective of system, so as to realize the overall optimization of the total system cost [23].

In the past three years, the system dynamics method has been developed and applied in the field of logistics, and a lot of research results have emerged. In addition, system dynamics modeling and simulation studies are conducted for different logistics systems, such as refined oil systems, agricultural systems, e-commerce return logistics [24]. And third-party logistics studies based on system dynamics [25]. It was noteworthy that the system dynamics in the logistics cost of the relevant research has also made some achievements. Dan HUANG used the system dynamics method to study the cost of timber production logistics, constructed the system dynamics model and simulated the development trend of the cost by means of Vensim simulation software, and proposed the optimization scheme to reduce the logistics cost [26]. It can be seen that the application of system dynamics method in the field of logistics research and broad prospects for development.

\section{$4 \quad$ Problems in the Study of Tobacco Logistics Costs}

Throughout China's history of the development of the tobacco industry in recent years, although the tobacco logistics construction work has made great achievements, has made some remarkable achievements in some aspects, but we must be constantly aware that China's current tobacco logistics construction work there are still many problems can't be ignored. For example, China's tobacco logistics in the tobacco industry system in each link or part of the distribution is too scattered, the smaller the scale of the logistics, it was difficult to achieve large-scale effect. And because of pedantic management methods, cost was difficult to keep in control at all times.

In addition, in the existing research results, scholars have done a lot of research on the control of logistics costs from various angles after in-depth analysis of logistics costs, but the research area was mainly reflected in the local one or several logistics costs, Such as inventory costs, transportation costs and so on. Because there are irreversible effects between the various functions 
of logistics, it is difficult to grasp the whole logistics cost as a whole, and the research results based on quantitative cost model are relatively few.

From the above analysis, it could be seen that the system dynamics method was an important and effective method to study the logistics cost problem, and some successful application cases have emerged in the field of logistics. However, according to the literature research results show that the system dynamics based on the cost of tobacco logistics research was still relatively small, some problems remain to be resolved or in-depth study.

\section{$5 \quad$ Conclusions and Reflections}

Generally speaking, the research on logistics cost in our country wants to be in line with the international standards, and the emphasis should also be shifted from the macro control level to the micro enterprise operational level. In the use of the theory of system dynamics analysis based on the tobacco logistics cost, create a system dynamics model of the total cost of logistics from the perspective of system, and based on the prediction and control of tobacco logistics cost optimization model, not only conforms to the reality, and which will improve the effectiveness of the control of logistics cost. The research results will help to enrich and perfect the theory of tobacco logistics, which provide the relevant theoretical basis for the formulation of feasible tobacco logistics system improvement program.

As the biggest cost of the construction and operation of commercial enterprises in tobacco industry, logistics cost was the key point to realize the transformation of traditional business model into modern circulation. At present, the nationwide logistics modernization of tobacco commercial enterprises has been carried out continuously, and the best balance between logistics cost and service quality has been explored.

\section{Acknowledgement}

This work was supported Science and Technology Project of Henan Science and Technology Department (162102110118), Horizontal project of Henan 863 Software Incubator Co., Ltd..

\section{Reference}

[1] Ruijiang WANG. (2010) Research On The Integrated Optimization Of Tobacco Logistics Systems. Beijing Jiaotong University.

[2] Lin LU. (2009) Studies On The Distribution Routing Problems In Tobacco Logistics. Journal of Anhui Agricultural Sciences, 2, 851-852.

[3] D. M. Lambert, J. R. Stock, L.M. Ellram. (1998) Fundamentals Of Logistics Management. Boston: Irwin/Mcgraw-Hill.

[4] Amy Z. Zeng, Christian Rossetti. (2003) Developing A Framework For Evaluating The Logistics Costs In Global Sourcing Processes. International Journal Of Physical Distribution \& Logistics Management, 9, 785-803.

[5] Outi Manunen. (2001) An Activity-Based Costing Model For Logistics Operations Of Manufacturers And Wholesalers. International Journal of Logistics: Research and Applications, L, 53-65.

[6] Carles Grifu-Miquela. (2001) Activity-Based Costing Methodology For Third-Party Logistics Companies. Iaer, L, 133-146.

[7] P. S. Bender, R.W. Brown, H. Isaac, J.F. Shapiro. (1985) Improving Purchasing Productivity At IBM With A Normative Decision Support System. Interfaces, 3, 106-115.

[8] A. C. Pan. (1989) Allocation Of Order Quantity Among Suppliers. Journal Of Purchasing And Materials Management, 3, 36-39. 
[9] W. C. Benton. (1991) Quantity Discount Decision Under Conditions Of Multiple Items, Multiple Suppliers And Resource Limitation. International Journal Of Production Research, 10, 1953-1956.

[10] S. H. Chodsypour, C. O’Brien. (2001) The Total Cost of Logistics in Supplier Selection, Under Conditions of Multiple Sourcing, Multiple Criteria and Capacity Constraint. International Journal Of Production Economics, 73, 15-27.

[11] Yanbo HUANG, Hanjiang ZHANG. (2004) A System Approach of Logistics Cost Control. Systems Engineering, L, 52-54.

[12] Zhaoyuan SUN, Qiyuan PENG, Xu CHEN. (2006) DEA Model for Logistics Activity Cost Control Of Enterprises. 5, 649-652.

[13] Jingya HAO, Yan ZHENG. (2013) Study On Logistics Cost Control Model Based On ERP Logic. Logistics Technology, 7, 272-274.

[14] Dezhi TANG. (2012) Study on The Tobacco Logistics Cost Control. Southwestern University Of Finance And Economics.

[15] M. M. Nami, D. R. Towill. (1994) Establishing A Frame Work For Effective Materials Logistics Management. International Journal Of Logistics Management, 1, 81-88.

[16] D. Berry, M. M. Nami. (1996) Quantifying the Relative Improvements of Redesign Strategies In A P.C. Supply Chain. International Journal of Production Economics, 46, 181-196.

[17] Towill D R. (1996) Industrial Dynamics Modeling of Supply Chains. International Journal Of Physical Distribution \& Logistics Management, 2, 23-42.

[18] A. Cakravastia, L. Diawati. (1999) Development of System Dynamic Model to Diagnose the Logistic Chain Performance of Shipbuilding Industry In Indonesia. International System Dynamics Conference, Wellington.

[19] B. Vos, H.A. Akkermans. (1996) Capturing the Dynamics of Facility Allocation. International Journal Of Operation \& Production Management, 11, 57-70.

[20] Chun SU, Lu SHAN, Yingqiu XU. (2007) Performance Evaluation of Supply Chain Based On Balanced Scorecard And System Dynamics Simulation. Industrial Engineering and Management, 5, 74-78.

[21] Wenjia CHEN, Dong MU. (2008) Research on Warehousing System At Distribution Center By System Dynamics. Journal Of Beijing Jiaotong University (Social Sciences Edition), 1, 27-32.

[22] Liping LI. (2012) The Research On Construction And Application Of System Dynamics Model Of Regional Logistics. Northeast Forestry University.

[23] Mengwei TONG, Tianzi CHAI. (2012) The Modeling Research Of 3PL Cost Based On System Dynamics. Journal Of Tangshan College, 25, 84-88.

[24] Yunxin DUAN. (2016) Research On The Return Logistics Management Of Electronic Commerce Based On System Dynamics. Tianjin University of Technology And Education.

[25] Chang XIA. (2015) Analysis Of Demand For TPL By Industrial Clusters Based On System Dynamics. Logistics Technology, 34, 171-175.

[26] Dan HUANG. (2013) Cost Influence Factors In Timber Cutting Area Based On System Dynamics. Journal Of Northeast Forestry University. 